\title{
REPRESENTAÇÕES DE UMA PROFESSORA SOBRE O PROCESSO DE ORIENTAÇÃO PARA REESCRITUTA TEXTUAL
}

\author{
REPRESENTATION OF A TEACHER ABOUT HER TEACHING \\ PRACTICE \\ IN THE PROCESS OF TEXT REWRITIG
}

\author{
Maria de Fátima ALMEIDA ${ }^{1}$ \\ Manassés Morais XAVIER ${ }^{2}$ \\ Symone Nayara Calixto BEZERRA ${ }^{3}$
}

\section{RESUMO}

Neste artigo buscamos refletir sobre a representação de uma professora de língua portuguesa acerca de sua prática de ensino no processo de reescritura textual e identificar objetos constitutivos de sua atividade docente; assim como eles são representados. A jutificativa de um estudo como esse encontra-se no fato de que segundo Bronckart e Machado (2004), o entendimento das ações do professor e de suas representações pode gerar a compreensão do trabalho docente. Para isso, ao analisar o texto da professora em resposta a uma entrevista, estamos nos apoiando nos postulados teóricos da Clínica da Atividade (CLOT, 1995 e FAÏTA 2002) e do Interacionismo sociodiscursivo (BRONCKART e MACHADO, 2004).

PALAVRAS CHAVE: Representações do professor; Ações; Clínica da Atividade.

\begin{abstract}
In this article, as well as reflecting on the representation of a Portuguese language teacher about her teaching practice in the processo of text rewritig, we also identify objects that constitute her teaching, as they are represented. The justification for such study lies in the fact that her teaching, as they represented. The justification for such study lies in the fact that according to Brockart and Machado (2004), the understanding of the teacher's actions and their representations can generate understading of teaching. Based on the theoretical postulates of the clinic Activity (CLOT, FAÏTA 1995 and 2002) end the Sociodiscursive Interactionism (BRONCKART and MACHADO, 2004) we analyze the texto $f$ the teacher in response to as interview.
\end{abstract}

KEYWORDS: Representations of the teacher; Actions; Clinico Activity.

\section{INTRODUÇÃO}

A profissão docente apresenta várias dificuldades em seu coletivo. Tanto os professores iniciantes são desafiados, quando se deparam com a demanda de atividades no processo de socialização de saberes; como os professores ditos mais experientes se sentem intimidados ao serem "cobrados" a utilizar técnicas de ensino mais "modernas" nas atividades realizadas com seus

\footnotetext{
${ }^{1}$ Doutora em Letras pela Universidade Federal de Pernambuco. Professora de Língua Portuguesa e de Linguística da Universidade Federal da Paraíba. E-mail: falmed@uol.com.br

${ }^{2}$ Doutorando em Linguística pela Universidade Federal da Paraíba. Professor de Língua Portuguesa e de Linguística da Universidade Federal de Campina Grande. E-mail: manassesmxavier@yahoo.com.br

${ }^{3}$ Doutoranda em Linguística pela Universidade Federal da Paraíba. Professora Substituta de Língua Portuguesa e de Linguística da Universidade Estadual da Paraíba. E-mail: symonebezerra@gmail.com
} 
alunos. Os professores chamados aqui de mais experientes são aqueles que já estão em sala de aula há algum tempo e precisam estar aptos a lidar com as mudanças no processo de ensino aprendizagem. Acreditamos que esse preparo advem de uma busca por uma formação continuada que lhes dá acesso a teorias trabalhadas nas esferas instituicionais.

Acreditando que a formação continuada é um processo de socialização de saberes importante para o fazer docente, muitas pesquisas estão sendo realizadas nessa área, tais como as desenvolvidas na formação em ensino à distância e capacitação de professores em ação. Pesquisas estas que servem de orientação para o desenvolvimento de projetos como o da formação continuada, promovido pela Universidade Estadual da Paraíba em parceria com o governo do Estado com o intuito de "melhorar" o fazer docente a partir do desenvolvimento de técnicas e manuseio de intrumentos que tendem a desenvolver e ampliar suas capacidades docentes.

Ao realizar pesquisas anteriores ${ }^{4}$ sobre o processo de orientação para reescritura textual, foi observado que há, por parte de muitos professores, uma preocupação em colocar em prática esses saberes mobilizados por esferas institucionais, a fim de promover um melhor desempenho de suas atividades. Percebemos, durante as entrevistas que realizamos após a aplicação das sequências didáticas dos professores, que muitos se sentiam frustados ao perceberem que não fizeram como haviam planejado ou ainda insatisfeitos pelo fato de, segundo eles, não terem experência e, consequentemente, não saberem fazer.

Segundo estes professores, há uma grande demanda de teorias e atividades que ajudam no aprendizado dos seus alunos, mas o acesso a determinadas ferramentas, principalmente as tecnológicas, é bastante restrito e isso faz com que muitas das tarefas designadas não possam ser realizadas, uma vez que uma grande parte desses profissionais não tem acesso a ferramentas tecnológicas que são expostas nas atividades de formação e nos livros didáticos.

Imaginamos que ao avaliar o texto do professor durante a entrevista, quando ele avalia sua prática, podemos entender a maneira como esses professores se apropriam e utilizam seus recursos para superar as dificuldades da profissão, isto é, entender a gênese instrumental (CLOT e FAÏTA, 2000).

Portanto, o objetivo deste estudo é refletir sobre a representação que uma professora de língua portuguesa faz de sua prática de ensino durante o processo de reescritura textual e identificar, na atividade dessa professora, quais são os objetos constitutivos e de que forma eles são concebidos por ela em sua atividade docente, assim como eles são representados.

Neste intuito, estamos nos apoiando no postulado teórico da Clínica da atividade com ênfase na noção de gênero profissional (CLOT, 2007) e no interacionismo sociodiscursivo (BRONCKART e MACHADO, 2004).

\section{Clínica da atividade: conceitos e apropriações}

A primeira referência à Clínica da atividade se deu a partir do livro "A função psicológica do trabalho", escrito por Yves Clot e publicado na França em 1999. O livro discute os caminhos percorridos pelas correntes francesas e pela Ergonomia, no entanto aproxima-se do conceito de atividade desenvolvido pela escola russa de Vygotsky e por isso lança mão de uma divergência conceitual e metodológica de que não basta considerar a atividade, é preciso tomá-la como uma história sempre incompleta, pois o objeto da clínica da atividade não é exatamente a atividade como tal, mas o desenvolvimento das atividades do sujeito e seus impedimentos (SILVA, BARROS e LOUSADA, 2011), pois segundo CLOT (2007 apud SILVA et al 2011), quando o trabalhador realiza uma tarefa, ele a transforma já que este não pode ser concebido como um simples sistema

\footnotetext{
4 Ver dissertação de mestrado SABERES LINGÜÍSTICOS SOBRE ESCRITA MOBILIZADOS POR PROFESSORES E ALUNOS EM PROCESSO DE REESCRITURA TEXTUAL (BEZERRA,2007).
} 
de execução da tarefa prescrita, uma vez que a tarefa se torna parte da história do trabalhador que possui objetivos pessoais durante a execução desta e, portanto, estes objetivos podem contribuir para a eficácia do trabalho.

No caso do trabalho docente, em que há uma preocupação em não transpor mecanicamente e em não ser um produtor de mercadorias Saviani $(1987,1997)$ aborda a natureza da docência como base na diferença entre trabalho material e trabalho imaterial, incluindo a docência como trabalho imaterial, já que se refere à produção de ideias, valores e conhecimentos.

Nesse trabalho imaterial, no qual está inserido o trabalho docente, alguns aspectos do processo são de suma importância e sobre isso Paro (2005), em sua teorização, desenvolve três aspectos que perpassam as análises feitas por Saviani:

1) o papel do educando no processo de produção pedagógica, pois ele afirma que a participação do aluno é fundamental para que o processo de ensino-aprendizagem ocorra; tal participação se dá na medida em que o aluno entra no processo ao mesmo tempo como sujeito e como objeto;

2) o conceito de produto da educação escolar significa mudança na forma de ser/viver do aluno que depende da ação conjugada de muitos dentro da escola;

3) que a natureza do saber envolvido no processo educativo escolar: o saber como instrumento aparece na produção pedagógica e se consubstancia em técnicas e métodos de ensino, contudo, no ato educativo, o saber se apresenta como matéria-prima que ao ser trabalhado se incorpora ao produto final.

A Ergonomia da Atividade surge paralelamente à Psicologia do Trabalho para questionar a Ergonomia francófona em que o trabalho seria uma atividade realizada por um indivíduo ou um coletivo e situada num contexto particular e estruturado por regras impostas. Para a psicologia do trabalho, a atividade de trabalho é uma fonte incessante de criação, onde o trabalhador inventa e reinventa prescrições quando estas não existem ou são imprecisas. Essa perspectiva é norteada por postulados vygotskyanos, nos quais o trabalhador não é considerado um simples realizador de tarefas, mas transforma sua própria atividade de trabalho e a si mesmo.

A ergonomia de vertente francesa surgiu em oposição às teorias e às práticas desenvolvidas nos Estados Unidos (fordismo e taylorismo), cujo objetivo era adaptar os indivíduos ao trabalho. O objetivo agora era uma abordagem antropocentrada, ou seja, o foco no funcionamento global do trabalhador, não apenas no que dele temos de observável, mas em toda sua multidimensionalidade que envolve seu funcionamento fisiológico, cognitivo, afetivo e social.

Essa vertente da Ergonomia apresenta duas noções centrais: trabalho prescrito e trabalho realizado em que o trabalhador é visto como um verdadeiro ator e não como um mero executor das prescrições. Frente a esse aspecto, o que era visto como "déficit" do trabalhador, passou a ser visto como elemento constitutivo da atividade de trabalho, como manifestação da inteligência criadora dos trabalhadores no confronto com a situação real em que se encontram. Neste sentido, ao discutir a contribuição da psicologia do trabalho, é relevante dizer que é a partir dela que podemos refletir sobre a distância entre a tarefa prescrita e a tarefa realizada sem sofrimento para quem a realiza, pois o trabalho real é constituido daquilo que o trabalhador faz e daquilo que deseja, faz, não deseja, deve e não deve fazer, pois segundo Lousada (2004), há uma distinção entre trabalho prescrito, real e realizado.

Como podemos ver, há um aspecto subjetivo ao analisar essas atividades, lidamos com aspectos que não podemos mensurar/observar, o que traz poblemas metodológicos para analisar o trabalho real e é exatamente aí, onde a Clínica da Atividade vai ser de grande auxílio, porque segundo essa teoria os conflitos são peças fundamentais para o desenvolvimento do trabalhador.

Claro que há conflitos que podem trazer tanto transtorno ao trabalhador que ocasionam a desistência. No entanto, se este tiver vontade de superar as dificuldades, pode contar com artefatos chamados de Gêneros da Atividade que são considerados um conjunto de regras explícitas e implícitas para o agir, construídas pelo próprio grupo de trabalhadores de uma determinada profissão com o intuito de resolver conflitos na realização de determinadas atividades. Segundo 
Faïta (2004, p. 69) "O gênero de discurso ou mais amplamente o gênero de atividade pode ocupar em espaço que se limita, de um lado, pela norma social e, de outro, pela capacidade de significar (agir) efetuando uma transformação - transgressão voluntária e consciente da norma ou do gênero dominante".

Faïa (2004, p. 64) afirma ainda que

o desenvolvimento da noção de gênero no campo da análise do trabalho requer o esclarecimento de duas questões: 1) De que conceito de gênero se trata nesse campo e 2) a que necessidade atende, principalmente, no domínio da análise da atividade. Assim, é importante aplicar ao trabalho do professor contribuições de trabalhos desenvolvidos em outros campos, atentando para: a) clareza do posicionamento teórico e epistemológico; b) Pertinência dos procedimentos; c) Demonstração da eficácia obtida com esses procedimentos.

Dessa forma, o gênero da atividade apresenta-se sob a forma de uma sucessão de momentos que oferecem aos atores problemas a serem resolvidos (p.61). São decisões/ escolhas surgidas nas situações de ação. A atividade, modo próprio de cada um reconstituir sua tarefa (SCHWARTZ 2001), põe em jogo uma dimensão intermediária, intercalada entre o meio e o sujeito, oferecendo soluções possíveis para os problemas e impasses e permitindo a reelaboração desses valores próprios. Refere-se às formas de pensar e de fazer do coletivo ou do grupo essa dimensão intermediária. É como se entre o sujeito agente e o seu meio tivesse as regras, normas, prescrições produzidas pelo coletivo/grupo.

A origem das normas pode ser situada por três fatores: a) Multiplicação das atividades semelhantes; b) Atividades frequentes de diálogo; c) Modo de avaliação das formas de agir e o grupo profissional que podem ser entendido como "um ator coletivo que pode se moldar, em função da semelhança das preocupações, de coerções reiteradas para a ação, sem que necessariamente realize escolhas e julgamentos explícitos, formalmente compartilhados e discursivizados". O fazer compartilhado corresponde a preocupações particulares no quadro de uma atividade comum ao conjunto de uma categoria sócio profissional o que nos permite falar de gênero. O gênero de discurso ou mais amplamente o gênero de atividade (CLOT e FAÏTA, 2000) pode ocupar em espaço que se limita, de um lado, pela norma social e, de outro, pela capacidade de significar (agir) efetuando uma transformação - transgressão voluntária e consciente da norma ou do gênero dominante. (p.69)

O trabalho do professor por seus gêneros trata-se das escolhas feitas pelos professores, por exemplo, ao se verem diante da dificuldade de fazerem seus alunos aprenderem regras abstratas da língua e concretas de leitura, ao mesmo grupo; provavelmente, essas escolhas/decisões dos professores marcam um gênero de atividade. A incorporação, no trabalho, de gestos, decisões, atitudes para dominar as situações da sala e atingir seu objetivo, torna-se marcas de um gênero de atividade. Trata-se de formas de fazer aparentemente comuns a um determinado grupo de professores.

Podemos afirmar, então, que o gênero da atividade nunca está acabado, o homem transforma o meio, antecipa sua conduta, revela comportamentos novos, individuais, únicos. A concepção de atividade é vista como algo coletivo, grupal, o produtor é quem as define. A atividade real, assim como declara Silva, Barros e Lousada (2011), é bem maior, mais ampla, com mais implicações e ações, do que a atividade realizada. A primeira inclui também aquilo não foi feito, o que foi suspenso, impedido de ser realizado por algum fato. Os gêneros de atividade profissional decorrem de regras que ainda não foram prescritas, do ponto de vista da escrita, mas estas regras passam a ser móveis, voláteis, fazendo com que os gêneros sejam inacabáveis e que o trabalhar recai sempre em uma dimensão coletiva, mesmo que seja desenvolvido por um só trabalhador.

Em suma, o gênero da atividade é um sistema de instrumentos, coletivamente construído e que se encontra na atividade. É um conjunto de atividades permitidas ou proibidas. Um repertório que pré-organiza a atividade e que possui formas de fazer estabelecidas pelo coletivo e dessa forma pode ser compreendida como a parte subentendida da atividade que apenas aqueles que participam do métier conhecem. Trata-se, pois, de um instrumento da atividade individual.

\section{Por que e como analisar o trabalho do professor?}


Para entender o trabalho do professor, vamos entender a diferença entre o trabalho industrial e o docente. Sobre isso, Tardif (2002), mostra a diferenciação entre trabalho industrial e trabalho no ensino e a natureza da relação entre professor e exercício profissional. Sobre o primeiro aspecto, o estudioso apresenta duas características principais para a diferenciação: a) objetivos que são mais precisos em uma indústria do que na educação escolar; b) $\mathrm{O}$ objeto de trabalho, o professor lida com sujeitos que possuem características individuais e ao mesmo tempo, são seres sociais, daí a indeterminação e complexidade. Segundo ele

Como qualquer trabalho, ensinar é perseguir fins e movimentar meios para tal, mas esse traço comum não obscurece as particularidades da docência. Existem aspectos que marcam especificidades no exercício profissional do magistério e na relação entre o professor e seu trabalho. (p. 49)

Abordando a questão das relações entre o professor e o exercício profissional, Tardif (op.cit) defende que para a realização do ensino na escola, da parte do professor, envolve-se:

a) O saber acadêmico: Entendido como teorias pedagógicas, das ciências da educação e dos saberes das disciplinas;

b) O saber curricular: Compreendido como programas escolares (objetivos, conteúdo programático etc.);

c) O saber experiencial: Diz respeito à realização do trabalho, em si; desenvolvimento (individual) e partilha com os colegas sobre procedimentos com as turmas, etc.(coletivo).

Ao abordar as teorias e métodos, ele corrobora com as proposições de Habermas (2012) e defende a ideia de que a abordagem do trabalho do professor por meio das teorias da ação permite enriquecer o estudo do saber docente uma vez que o trabalho contínuo com esses conhecimentos faz com que o professor se avalie perceba aspectos importantes de sua prática. A questão é que as teorias da ação não parecem oferecer abrigo para o trabalho compreendido como atividade humana. Deixam escapar as riquezas que se apresentam na distinção entre trabalho prescrito e trabalho real para centrar sua atenção sobre a ação e o saber a ela imanente.

É importante compreender por que a questão do trabalho educacional atualmente é tão confusa; assim como suscitar alguns problemas relacionados à questão do trabalho em geral, principalmente o problema da relação entre o trabalho e a ação humana e o do papel e do estatuto da ação no funcionamento humano. Bronckart (2007), expõe também a dificuldade em descrever esse trabalho sua "relativa opacidade" em caracterizá-lo ou simplesmente falar dele.

O interesse pelo trabalho do professor se explica ao analisarmos o resultado da evolução "natural" dos trabalhos de didática das disciplinas e da instauração das escolas públicas e obrigatórias no último quarto do século XIX, em todos os países, pois a partir dessa mudança os sistemas de ensino passaram a ser frequentemente objeto de movimentos de reforma e/ou de renovação para acompanhar novas expectativas decorrentes das revoluções sociais e econômicas que ocasionaram o surgimento de novos conhecimentos sobre os conteúdos das disciplinas escolares, principalmente, no campo científico.

Essa adaptação, inicialmente, consistiu em uma aplicação direta que ocasionou grandes mudanças no que se refere ao ensino de língua, no entanto não tiveram a eficácia esperada devido a duas razões: primeiramente porque não podemos agir sobre a escola sem considerarmos sua realidade e em segundo lugar pelo fato de ser pertinente a aplicação direta de conhecimentos científicos sem que esses conhecimentos sejam selecionados, transformados e simplificado para poderem ser compreendidos pelos alunos.

É necessário ressaltar que os conhecimentos só são “assimilados” pelos alunos se houver uma adequação na transposição/mobilização desses saberes e nesse processo é preciso considerar todo o contexto escolar, tais como os objetivos dos programas, o método de ensino, o grau de letramento dos alunos, assim como a formação desses professores que estão responsáveis pela aplicação desses conhecimentos.

Para solucionar esses problemas, entre os anos 60/70 as didáticas das disciplinas escolares 
sugiram baseadas em um trabalho triplo constituído pela análise do estado de ensino de uma determinada matéria, a análise aprofundada dos aportes das disciplinas e trabalhos de pesquisa e de intervenção que visam a melhorar o estado de ensino com a introdução de conceitos e métodos oriundos do campo científico, sempre objeto de uma transposição ${ }^{5}$.

O ensino de língua, a partir dessa nova perspectiva, assumiu um novo perfil, resultado de uma redefinição do projeto de ensino que ocorreu a partir da modificação da sua organização e da sua planificação temporal, melhoria do nível dos instrumentos de ensino, produção de sequências didáticas e nível de procedimentos e dos conteúdos de avaliação da aprendizagem dos alunos.

Todos esses procedimentos geraram, portanto, outra preocupação: a realidade do trabalho educacional e/ou a especificidade do ofício de professor reforçada pelos aportes dos trabalhos da ergonomia francesa europeia e de uma corrente mais recente: análise do trabalho que mostra as diferenças fundamentais entre o trabalho prescrito e o trabalho real. Nesta perspectiva, surgem dúvidas tais como definir a ação ou a atividade humana e as suas características. Bronckart(2006) afirma que o trabalho se constitui, claramente, como um tipo de atividade ou de prática. Mas se o trabalho é um tipo de atividade, o que é a atividade (ou a ação, ou o agir)? A atividade seriam os comportamentos, as condutas, as intervenções que todos nós desenvolvemos, todos os dias. Para explicar as condições de operalização dos conhecimenos nas práticas humanas, Bronckart aponta três teorias:

- A primeira é a da filosofia da ação (reformulada por Ricoeur, 1977) sob o nome de semântica da ação. Essa corrente distingue os acontecimentos que se produzem na natureza das ações propriamente ditas, para ele uma ação é uma intervenção deliberada de um agente humano no mundo, em que o agente que intervem tem um motivo ou razão para agir, uma intenção, capacidade e consequentemente responsabilidade.

- A teoria oriunda da atividade dá enfase às dimensões primeiro coletivas do agir humano no decorrer de sua hitória social. Nesta perspectiva, a atividade é primeiramente governada por motivações, finalidade, regras de ordem coletiva e social e exercem efeito restritivo sobre os comportamentos efetivos dos indivíduos que, portanto, possuem um espaço de liberdade e criatividade muito restrito.

- A terceira concepção é uma espécie de compromisso entre as duas anteriores. Nesta, concebe-se a ação como um processo de pilotagem dos comportamentos em redes de restrições múltiplas que podem ser internas ou externas. Essa corrente, portanto, atribui uma importância um papel impotante ao sujeito individual.

Portanto, considerando essas três abordagens, o que se chama de atividade ou de ação é resultado de um processo interpretativo. O que é observável são os comportamentos humanos e qualificar esses comportamentos de atividade, de ação ou de pilotagem implica que atribuamos aos protagonistas coletivos ou individuais desses comportamentos determinadas propriedades que não são diretamente observáveis, mas sobre as quais podemos pensar razoalvemente que elas orientam ou determinam esses comportamentos.

\subsection{A atividade do professor: gêneros e artefatos}

Como podemos verificar ao longo de nossa discussão, a problemática da clínica da atividade reside na relação entre a tarefa organizadora prescrita e a atividade efetiva e concreta do trabalho. Como para muitos estudiosos o trabalho do professor se enquadra no trabalho real, este é visto como sujeito da atividade que vivencia conflitos dele com ele mesmo, das atividades que lhe é prescrita, dele com os artefatos e dele com os outros. E por isso, ao investigar o trabalho do professor, o pesquisador deve enfocar todas as interações do professor antes e depois do agir. É importante lembrar que para a Clínica da atividade, o trabalho do professor não é uma atividade

\footnotetext{
55 Edmilson Luiz Rafael em sua tese de doutorado" Construção dos conceitos de texto e coesão textual: da linguística à sala de aula" (Campina 2001) traz define os movimentos de transposição como sendo de dois tipos: solidarização e sobreposição
} 
dirigida exclusivamente ao aluno, mas à instituição na qual ele trabalha, aos pais e a outros profissionais, que formam o coletivo do trabalho. Vejamos o que Silva et al (2011, p. 193) afirmam:

O gênero pode ser definido como um corpo intermediário entre os sujeitos, um interposto social situado entre eles, e entre o objeto de trabalho. Um gênero sempre vincula entre si os que participam de uma situação, como coautores que conhecem, compreendem e avaliam essa situação da mesma maneira.

Apesar de existerem uma quantidade significativa de pesquisas sobre atividade docente, a maioria realiza descrições tendenciosas em que o fazer do professor é apenas obedecer às prescrições pré - estabelecidas em determinadas teorias e através de algum artefato. No entanto, esse quadro vem se modificando e essas representações do trabalho do professor vêm sendo esclarecidas a partir de uma abordagem ergonômica.

Conforme Bronckart e Machado (2004), as atividades realizadas pelo professor não se tratam de ação e sim de agir, pois a interpretação é sempre coletiva. Ainda segundo eles, a atividade docente envolve a articulação de várias ferramentas, a análise do que pode ou não ser realizado em sala, a reflexão mental daquilo que não foi realizado e do que foi realizado, a mobilização de conhecimentos e envolvimento com os alunos. Para Machado (2007, p. 92), trabalho é

uma atividade em que um determinado sujeito age sobre o meio, em interaçaõ com diferentes 'outros', servindo-se de artefatos materiais ou simbólicos construidos socioistoricamente, dos quais ele se apropria, transformando-os em instrumentos para seu agir e sendo por eles transformado.

Em relação aos artefatos, Amigues (2004) nos apresenta quatro objetos que são constitutivos da atividade de professor e que serão foco de nossa análise. Segundo ele, esses objetos são os mediadores no trabalho planificado, que constitui-se na intermediação entre parte do prescrito e parte do realizado; é o prefigurativo das ações do professor; são textos produzidos por formadores, mediante documentos institucionais, a fim de instruírem tarefas, objetivos, condições materiais da ação docente, que auxiliarão na formação pessoal e profissional. Esses objetos são:

a) prescrições: reorganizam o meio do trabalho docente e dos alunos, podendo rever prescrições que são consideradas vagas; a prescrição inicial tende a ser revista, reformulada, adaptada, mediada por uma organização de um meio com formas coletivas; mesmo estando voltadas ao coletivo, não são definidas pelo professor, já que seguem uma hierarquia, um planejamento;

b) coletivos: consiste na mobilização e organização do local de trabalho para obter um resultado às prescrições; o (coletivo) dos professores dificilmente é validado, a tendência é mascarálo e/ou desconsiderá-lo; os docentes podem organizar seu ambiente de trabalho e se organizar para elaborar uma resposta em comum a uma dada prescrição; Amigues (op.cit) chama a atenção para o fato de que apesar de o coletivo dos professores autoprescreverem as tarefas, cada um, ao seu modo, redefine (autoprescrições) suas metas, mesmo que não sejam estimulados a isso; como cada professor está associado a um dado coletivo, podemos relembrar a noção de gênero profissional.

c) regras do oficio: une os profissionais entre si; consiste numa memória em comum; com o tempo, podem renovar os gestos, os modos de fazer, passando a ser o alvo de controvérsias profissionais; inclui os gestos genéricos, voltado ao conjunto dos professores (ex.: fazer silêncio, entrar numa sala) e os específicos (às disciplinas).

d) ferramentas: são subservientes às técnicas do ensino; ex.: livro, internet, plano de aula; manuais, fichas, exercícios prontos, ditados; são concebidas por outros sujeitos ou pelo próprio professor para organizar a própria atividade, ou seja, consiste numa relação subjetiva, voltada à história de vida profissional do sujeito; os docentes fazem uso (de ferramentas) adotadas por outros colegas, podendo ser transformadas por aqueles para reverem seu agir e obterem eficácia; uma ferramenta pode ser transformada em um instrumento do pensamento (ou da ação), intitulada de gênese instrumental. 
A gênese instrumental serve para reorganizar a própria atividade; inclui-se dentro dos coletivos, que podem ser: professores de disciplina, de turma, de área, de conteúdo e de alunos; está voltada ao instrumento do pensamento do professor e dos alunos; a estes, contrariamente ao que se pensa, a transformação não ocorre de uma única vez, em todos os alunos; ela é concomitante ao pensamento cognitivo de cada um.

Para Faïta (2004), é a partir do coletivo e de suas regras que os trabalhadores agem e por isso mesmo o gênero profissional é constituído por muitos atos adequados ou não com os quais o professor precisa lidar e se adequar. Comumente, o professor precisa mediar os sujeitos participantes do coletivo de trabalho, suas ferramentas e regras do ofício para o cumprimento de suas atividades. Nesse contexto, parece-nos que o professor mais experiente possui melhor condição de se articular no gênero profissional, mas isso não quer dizer que ele saiba lidar com todos os contextos de produção uma vez que no contexto de sala de aula o profissional mobiliza diversos saberes e ferramentas e pode, em determinado momento, ter que mobilizar uma ferramenta nova, por exemplo. O que não garante a representação de sucesso por parte de quem a utiliza, o professor.

\section{A discussão dos dados}

Os dados analisados neste estudo são resultado de uma entrevista realizada com uma professora de língua portuguesa de uma escola pública de Campina Grande após a aplicação de uma sequência didática ${ }^{6}$ em uma turma de $1^{\circ}$ ano do Ensino Médio. Vale salientar, que no momento em que foi realizada, essa entrevista teve o objetivo de esclarecer algumas ações da professora (aqui chamada de PI) sobre sua atitude avaliativa no processo de reescritura de texto de seus alunos.

Apesar de a entrevista ter sido realizada com intuito diferente do que está sendo utilizado neste estudo, o fato de a professora ser questionada sobre algumas atividades realizadas por ela, fez com que houvesse uma auto avaliação de sua prática. Dessa forma, a retomada da referida entrevista proporcionou uma representação da prática desta professora no processo de orientação para reescritura.

No período da entrevista, PI lecionava em escolas públicas da rede estadual há 25 anos, 10 deles destinados ao ensino médio; e no período da pesquisa, ministrava aulas no $1^{\circ}$ ano do ensino médio. Ela concluiu sua graduação em Letras no ano de 1983 e a Especialização em Língua Portuguesa e Literatura Brasileira em 1993, na UFPB. PI afirmou participar de capacitações promovidas pelo governo assim como, na época, mostrou-se interessada em realizar uma pósgraduação a nível de mestrado por sentir-se "desatualizada".

Gostaria de ressaltar que PI nunca havia realizado uma sequência didática que resultasse em uma reescritura, mas afirmou que o livro didático adotado pela escola sempre ressaltava o valor dessa atividade.

\subsection{Entendendo o contexto de produção, reescritura e entrevista}

A sequência didática seguiu o seguinte percurso: inicialmente, a professora trouxe vários textos do gênero "crítica" de diversos suportes (revistas, jornais e livros) e leu com os alunos, tentando explorar as características comuns a esse gênero. Os alunos, junto com a professora, elencaram as características do texto e determinaram que toda crítica precisa seguir o padrão detectado pela turma, que seria uma introdução caracterizando o objeto cultural ,ou seja, quem é o diretor do filme, onde ele foi gravado, em que ano; se o diretor possui outros sucessos, quem são

\footnotetext{
${ }^{6}$ Essa entrevista faz parte do processo de coleta de dados da dissertação de mestrado "SABERES LINGÜísTICOS SOBRE ESCRITA MOBILIZADOS POR PROFESSORES E ALUNOS EM PROCESSO DE REESCRITURA TEXTUAL" e tinha como objetivo esclarecer algumas atitudes da professora frente a avaliação realizada dos textos reescritos pelos alunos.
} 
os atores; além disso resumir o enredo do filme e realizar uma avaliação crítica da obra. Essas características foram observadas coletivamente e expostas na lousa por PI.

No segundo encontro, a professora conduziu os alunos à sala de vídeo e eles assistiram a um filme que serviu para a produção de uma crítica. Seria importante ressaltar que a turma já foi à sala de vídeo consciente de que a obra seria utilizada para a produção de uma crítica na sequência das aulas.

No terceiro momento, os alunos foram orientados a produzir uma crítica do filme assistido no último encontro. Estes foram orientados a iniciarem a produção (em dupla) na aula, mas eles tiveram a oportunidade de concluírem a produção em casa e entregarem na aula seguinte. Como a professora precisava de tempo para corrigir os textos, ela os devolveu com a avaliação em forma de nota, assim como, com algumas anotações que nortearam a reescritura, uma semana depois. As anotações realizadas pela professora nos textos dos alunos, assim como os comentários realizados por ela em sala de aula, serviram para orientar a reescritura que também foi quantificada posteriormente.

Como nós tiramos cópia de todos os textos escritos e reescritos, percebemos algumas "inadequações" avaliativas. Por exemplo, textos em que havia fuga total ao gênero solicitado com nota ou textos que a reescritura foi apenas um "passar a limpo", mas teve um aumento significativo da nota. Por essas atitudes, resolvemos realizar uma entrevista que, na época, teve o objetivo de entender os critérios avaliativos da professora, mas acabou se tornando, em alguns momentos, uma atividade de auto avaliação por parte de PI e representação da sua atividade docente, como veremos ao longo da análise.

\subsection{Por que eu fiz assim?}

Para analisarmos a entrevista com a finalidade de refletirmos sobre a representação que a professora faz de sua prática de ensino e identificar os objetos constitutivos de sua prática e como são concebidos por ela, nos apoiamos na categoria de análise os objetos constitutivos da atividade docente (AMIGUES, 2004). E pudemos perceber que todos os objetos constitutivos foram encontrados na sua fala. Primeiramente, discutamos a questão da prescrição. Ela é ressaltada direta e indiretamente em diversos momentos. Comecemos pelo fato de PI resolver inserir a reescritura em suas sequências didáticas, por exemplo. Ela mesma afirma que não fazia reescritura, passou a fazer motivada por dois fatores: o livro didático trazer na sequência da unidade a orientação para produção seguida da reescritura e o fato de seus colegas já realizarem essa atividade como vemos nesse trecho da entrevista ${ }^{7}$.

É importante ressaltar que o livro utilizado pela professora, na época, era o livro "Português Linguagens" de Cereja e Magalhães, volume único, adotado por toda a rede de ensino do Estado da Paraíba e por algumas escolas da rede privada de Campina Grande e, talvez, por isso PI sempre fazia ótimas referências a ele, apesar de diversas vezes não conseguir seguir as orientações propostas por ele, em suas atividades docentes.

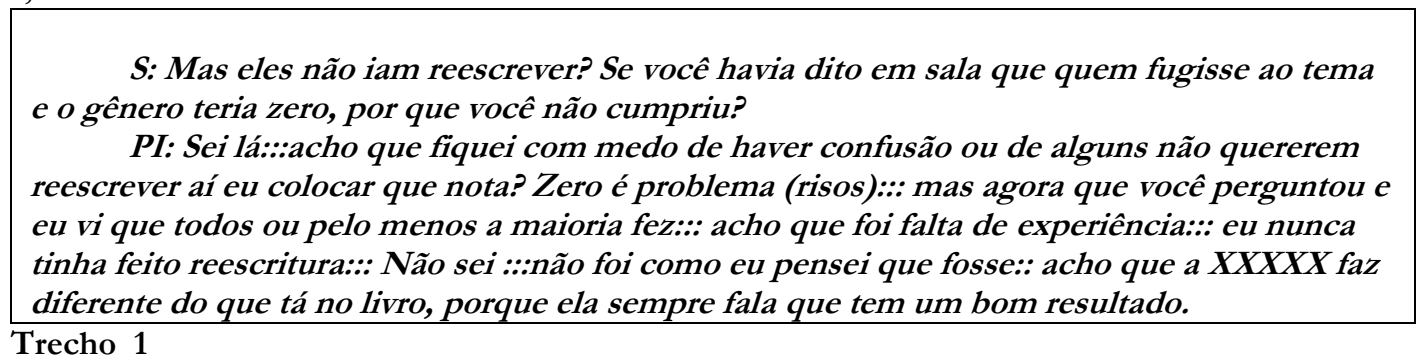

\footnotetext{
${ }^{7}$ Nos trechos da entrevista, $\mathbf{P I}$ trata-se do professor informante, $\mathbf{S}$ refere-se à pesquisadora e A1 e A2 aluno $1 \mathrm{e}$ aluno2.
} 
Observemos que nesse trecho há uma prescrição implícita que ocorre porque outros professores já realizam essa atividade e que há uma preocupação com o coletivo. Vejamos que ela reflete sobre a atribuição de nota e sobre as mudanças que podem ser realizadas para atender melhor àquela atividade. Ela inicia, nesse trecho, uma reflexão sobre auto prescrições ao dizer que sua colega faz diferente do livro, fugindo das prescrições do manual.

Ainda nesse trecho, é possível verificar uma preocupação implícita com as regras de ofício e coletivo quando ela diz "Zero é problema". Como sabemos, os alunos querem uma motivação para realizar uma atividade e ao analisar o discurso da professora, percebemos que ela possui consciência disso, inclusive ela afirma que ficou com medo de os alunos criassem confusão, uma vez que faz parte das regras de ofício, o professor atribuir notas às atividades realizadas pelos alunos, inclusive há uma postura preocupante no que diz respeito a avaliar o texto que foge ao gênero e/ou tema. Ela deixa claro que o zero é "mal" visto pela comunidade escolar.

Outro ponto importante que vamos perceber que apesar de PI valorizar o livro didático, uma de suas ferramentas, ao longo da entrevista, em diversos momentos, em conversas informais, a professora questiona as orientações do livro e afirma acreditar que quando sua colega realiza as atividades propostas com sucesso, faz mudanças como vimos no trecho "acho que a XXXXX faz. diferente do que tá no livro, porque ela sempre fala que tem um bom resultado".

Em diversos momentos, ao se avaliar e perceber inadequações, PI aponta as regras de ofício e o coletivo como culpados da falta de êxito. Como podemos verificar a seguir:

S: professora, eu estava observando as produções e percebi que em algumas delas você escreveu que o aluno não havia contemplado o que lhe foi solicitado, mas mesmo assim você atribuiu uma nota. Por quê?

PI: Ahh Symone:: foi mesmo. Eu dei uma nota porque se a gente não coloca uma nota, os alunos não levam o exercício a sério e também tem aquela caderneta que precisa ser preenchida. A coordenação exige, sabe?

S: Como assim? Não foi como você pensou?

PI: olha, Symone! Acho que não vi diferença entre o que eles escreveram na primeira versão do que eles escreveram na reescritura. Talvez eu precisasse de mais tempo para fazer isso::: essa greve atrapalhou tudo e agora a gente tem que correr para fechar:::0:::semestre.

Trecho 2

É possível perceber que, ao ser questionada sobre a nota, a professora percebe a inadequação/falha, mas aponta um objeto constituinte do sistema: as regras de ofício como elemento que influencia esta atividade e causa essa atitude; pois como sabemos, os alunos precisam ser avaliados e consequentemente o professor precisa atribuir uma nota a esse aluno, uma vez que, para ser promovido este aluno precisa ter suas notas registradas na caderneta e faz parte do ofício de professor preencher essas notas em tempo hábil e talvez por isso mesmo ela tenha se referido à greve, pois uma vez havido greve é provável que o tempo para execução de determinadas atividades tenha se tornado reduzido o que remete também a um coletivo, já que PI precisará satisfazer regras da instituição.

Como já foi dito anteriormente, os quatro objetos constituintes do sistema foram identificados na fala da professora. No entanto, percebemos que as prescrições, as regras de ofício e as ferramentas foram mais evidenciadas, conforme podemos constatar mais uma vez no trecho a seguir:

S: sei, mas mesmo você dizendo que não há diferença entre os textos da primeira versão para a segunda, você aumentou todas as notas.

PI: (interrompendo minha pergunta)...mas se eu não aumentasse como seriam esses resultados? Mas eu acho que não deveria ter colocado a nota na primeira versão não e talvez se eu tivesse escrito mais sobre os defeitos do texto :::não sei:::talvez tivesse ajudado os meninos.:::::: tenho que rever isso:::essa prática:::eu tentei seguir o plano de aula direitinho::ou melhor, a sequência didática do gênero proposta pelo livro, mas não deu certo. 


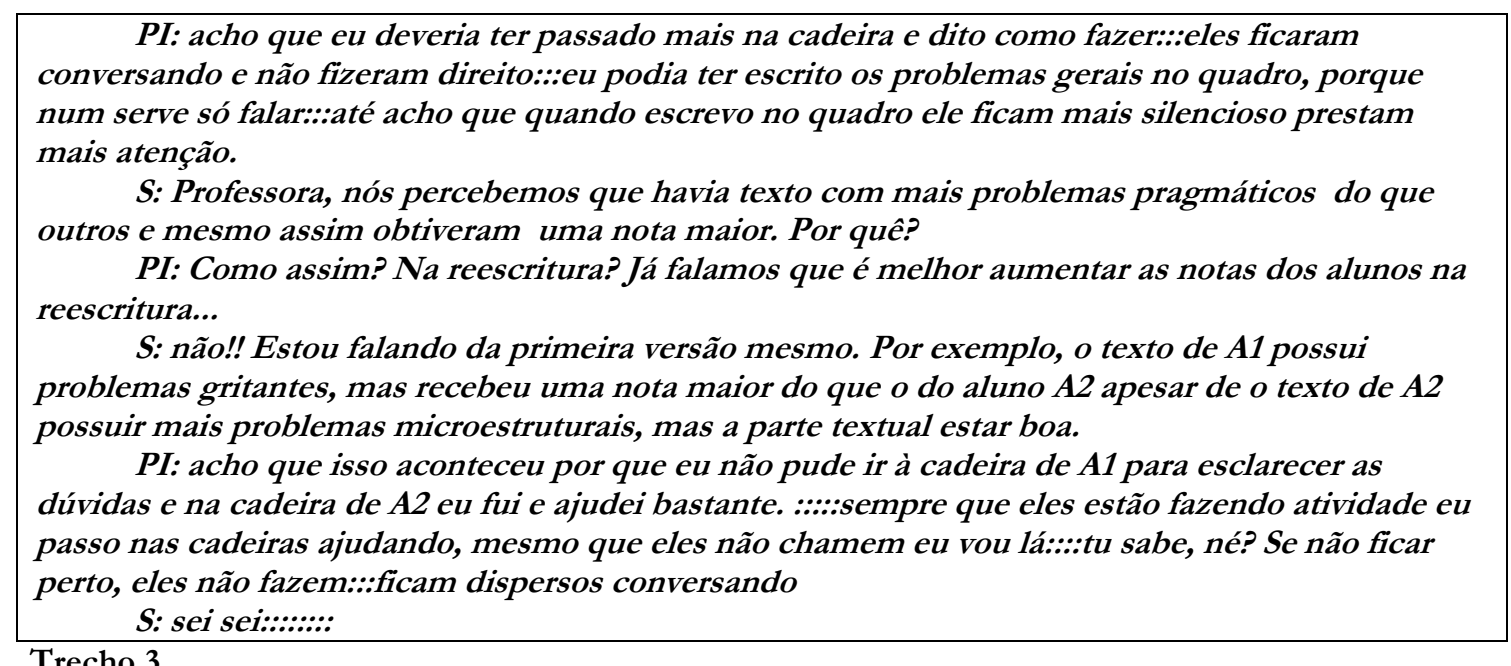

Trecho 3

Ainda nesse trecho da entrevista, podemos perceber uma preocupação com o as dimensões coletivas da atividade do professor. Por exemplo, quando PI diz " mesmo que eles não chamem eu vou lá:::tu sabe né? Se não ficar perto, eles não fazem::ficam dispersos conversando" mostra a preocupação com a organização do grupo. Essa atitude segundo Espinassy (2003, apud AMIGUES, 2004) pertence a um coletivo mais amplo, o da profissão; uma vez que faz parte do ofício do professor organizar a sala, conduzir as atividades, estabelecer a ordem. Ela reavalia sua atitude e percebe que o coletivo, o fato de existir uma maneira de organizar as tarefas para os alunos, foi inadequado e reavalia: "acho que isso aconteceu por que eu não pude ir à cadeira de A1 para esclarecer as dúvidas e na cadeira de A2 eu fui e ajudei bastante.:::::sempre que eles estão fazendo atividade eu passo nas cadeiras ajudando, mesmo que eles não chamem eu vou lá::::tu sabe, né? Se não ficar perto, eles não fazem:::ficam dispersos conversando"

Entretanto, esse trecho também aponta uma preocupação com o que foi feito e o que não foi feito (trabalho real) no momento de orientação. A estratégia de ir às carteiras dos alunos para orientar e esclarecer dúvidas faz parte das regras de ofício de PI inclusive ao ponto de a professora estabelecer critérios avaliativos partindo desta conduta de seu ofício.

Outro ponto que precisa ser ressaltado é o fato de PI está bastante condicionada à utilização do livro didático, sua ferramenta; e consequentemente à sequência didática proposta por ele ( a professora menciona uma sequência didática, mas não há como sabermos se foi elaborada por ela ou se ela está seguindo a do Livro do professor. Pelo contexto, acreditamos que é a sugerida pelo manual didático) e isso mostra mais uma vez a preocupação com a prescrição. Vejamos mais um trecho:

Não sei :::não foi como eu pensei que fosse:: acho que a XXXXX faz diferente do que ta no livro, porque ela sempre fala que tem um bom resultado.

Olha, Symone:::assim:::eu gostei de ter feito porque perdi o medo, mas acho que mudaria muitas coisas:::aliás:::já irei mudar muitas coisas. A questão, por exemplo, da sugestão do filme feita pelo livro:::achei que poderia ser outro, sabe? Algo mais didático::: assim acho que a ordem de introdução do gênero não foi ruim...essa coisa de ler apresentar os textos, discuti-los para poder pedir a produção é o que todo mundo faz, mas acho que da próxima vez vou fazer bilhetes como a minha colega $x \times x \times x$ faz dizendo o que tem de melhorar no texto... acho que isso vai ajudar os alunos a não passarem a limpo o texto e não coloco nota na primeira versão porque obriga eles a fazerem a segunda versão.

Trecho 4

Esse trecho é bastante interessante, pois deixa claro a gênese instrumental que a faz está inserida no gênero profissional. Ao fazer sua representação diante daquela atividade, ela percebe que as estratégias utilizadas para isso não são funcionais para o seu objetivo. PI percebe que as orientações foram insuficientes, que o filme sugerido pelo manual didático não contribuiu para a produção do gênero crítica no contexto selecionado, o que faz com que ela já gere suas 
autoprescrições para a próxima sequência de produção textual. Isso provavelmente aconteceu porque a professora apesar de nunca ter privilegiado a reescritura em suas sequências de produção, reconhece as finalidades discursivas do processo de produção de texto e reconhece, também, que neste momento da análise, não atende às representações tidas como regras para o estabelecimento de um ofício funcional na realização desta tarefa.

Em outro momento da entrevista, PI faz referência às ferramentas. Segundo ela, algumas ferramentas que são disponibilizadas pela escola poderiam ajudar na obtenção de um bom resultado, mas ela aponta algumas dificuldades para a utilização dessas ferramentas que vão desde a falta de habilidade de PI à dificuldade de utilização do recurso por falta de acesso. Vejamos o trecho 5:

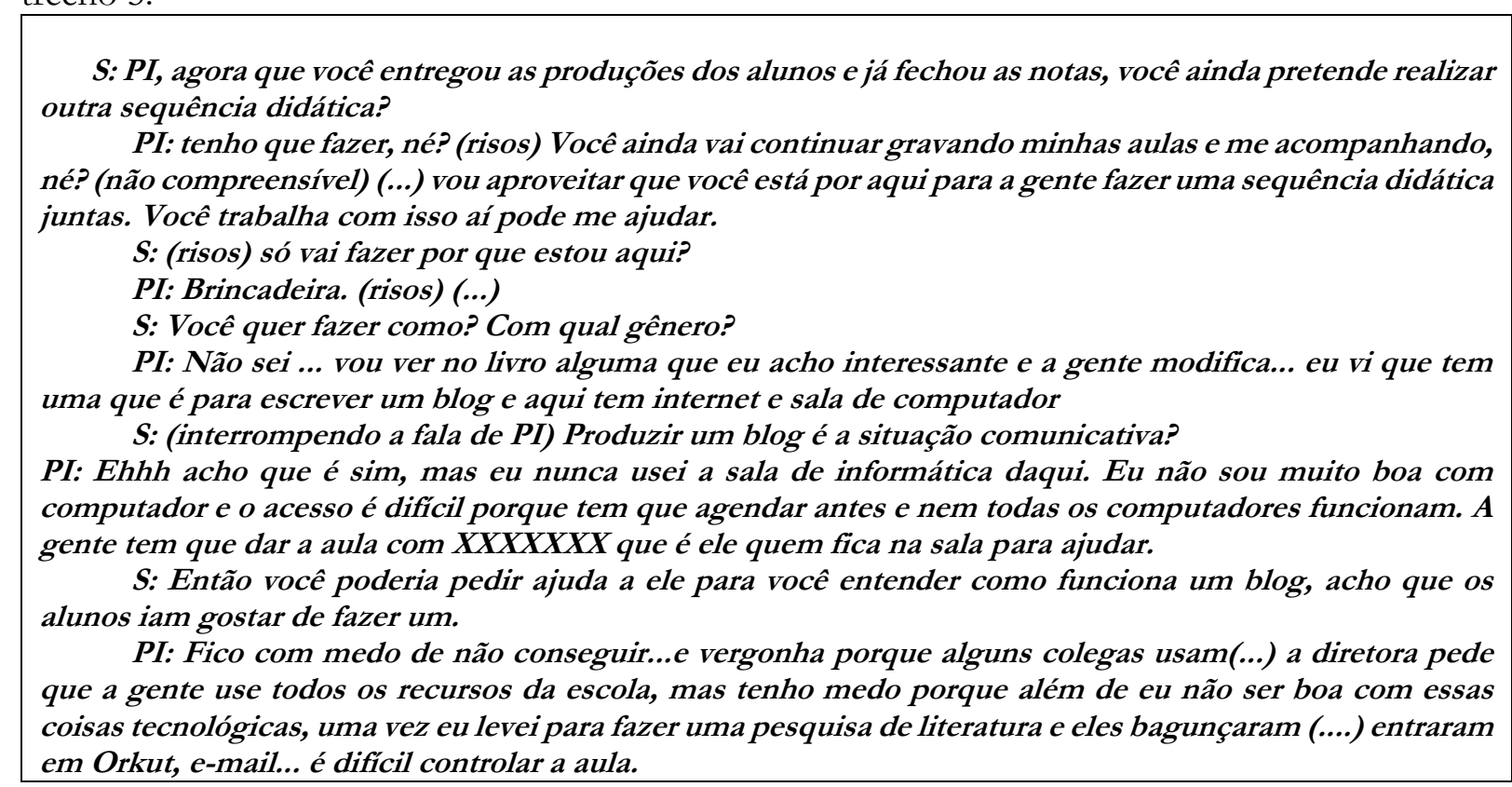

Trecho 5

Esse trecho também é bastante interessante para observarmos a gênese instrumental da professora. Ao realizar a reflexão de sua prática, ela passa a considerar outras estratégias para realizar seu trabalho. Ela ressalta a possibilidade de utilizar outras ferramentas, tais como internet/computador, no entanto, é perceptível que a professora não tem habilidade com a ferramenta citada, porque em dado momento da entrevista afirma: "Ehhh acho que é sim, mas eu nunca usei a sala de informática daqui. Eu não sou muito boa com computador e o acesso é difícil porque tem que agendar antes e nem todos os computadores funcionam. A gente tem que dar a aula com XXXXXXX que é ele quem fica na sala para ajudar". Neste mesmo trecho, percebemos dois momentos de prescrição implícita: a preocupação em realizar outra sequência que resultasse em uma reescritura porque a pesquisadora estava acompanhando suas aulas "tenho que fazer, né? (risos) Você ainda vai continuar gravando minhas aulas e me acompanhando, né? " e quando faz referência à solicitação da diretora "a diretora pede que a gente use todos os recursos da escola".

A professora aponta, também, uma preocupação voltada para o coletivo. A insatisfação em relação a sua última experiência na sala de computadores por não conseguir estabelecer a ordem, uma vez que os alunos não cumpriram suas ordens em relação a não acessar redes sociais e e-mail e estar sendo observada ao não conseguir realizar essa tarefa com êxito "uma vez eu levei para fazer uma pesquisa de literatura e eles bagunçaram (....) entraram em Orkut, e-mail... é difícil controlar a aula"; afinal controlar a aula é , também, uma regra de ofício do professor.

A preocupação em seguir o livro didático é mais uma vez ressaltada, pois mesmo ela tendo pedido ajuda a pesquisadora, no caso eu, que estava acompanhando as aulas e tinha se disposto a ajudar, ela disse que ia olhar o que havia de sugestão no livro. Ou seja, existe uma posição de credibilidade em relação ao uso do livro didático, mesmo que em outros momentos ela deixe 
claro o fato de acreditar que seus colegas fazem diferente do que está prescrito no material didático, para obter sucesso.

Outro ponto interessante é o fato de PI se mostrar envergonhada com a presença de um colega de outra área assistindo sua aula. Observemos a maneira como ela se reporta ao colega de informática. É bastante explícito o desagrado por parte de PI em ter que receber auxílio de um colega. Entretanto, sabemos que numa perspectiva de aprendizagem essas parcerias podem gerar resultados bastante satisfatórios.

Apesar de a entrevista, como foi dito anteriormente, ter uma finalidade diferente da que foi proposta para este estudo, pudemos perceber que ao ser questionada a professora se interessa por fazer uma "transformação" no processo de mobilização de saberes na sua aula; como podemos perceber na sua "fala" ao pedir ajuda a pesquisadora "vou aproveitar que você está por aqui para a gente fazer uma sequência didática juntas. Você trabalha com isso aí pode me ajudar". Não era intuito nosso realizar capacitação com PI, como também não é agora, neste estudo. No entanto, é preciso dizer que seja por uma prescrição da profissão e/ou motivação pessoal, a professora reavaliou sua conduta e deixou claro o interesse por realizar seu trabalho de maneira mais eficaz.

\section{ALGUMAS CONSIDERAÇÕES}

O trabalho docente não se trata de uma atividade individual e não está relacionada, apenas, à sala de aula. O professor prescreve suas tarefas e a dos alunos, organiza o trabalho coletivo em sala, e ainda planeja, organiza as situações futuras; portanto, não está limitado a ação. Seu trabalho é um ofício, uma atividade coletiva que possui o objetivo de desenvolver atividades docentes e discentes e estes últimos não se apropriam da ferramenta adotada pelo professor imediatamente.

Para Machado (2007) assim como Amigues (2004), O objeto do trabalho do professor consiste em criar um meio propício para a aprendizagem de conteúdos específicos e para o desenvolvimento de capacidades específicas. Sendo assim, o trabalho do professor constitui-se de uma mobilização, pelo professor, de seu ser integral, em diferentes situações de planejamento, de aula, de avaliação visando potencializar o objeto de trabalho.

Por fim, para desenvolver plenamente seu trabalho e obter efeitos positivos para si mesmo, o professor precisa ter recursos materiais e simbólicos internos e externos a fim de: reelaborar continuamente as prescrições; escolher, manter, ou reorientar seu agir de acordo com as necessidades de cada momento; apropriar-se de artefatos, transformando-os em instrumentos por si e para si; selecionar instrumentos adequados a cada situação; servir-se de modelos do agir sociohistoricamente construídos por seu coletivo de trabalho; encontrar soluções para conflitos dos mais diversos.

Como pudemos perceber, o trabalho do professor é uma atividade coletiva que não se restringe apenas à sala de aula e que envolve inúmeras ferramentas para atender seus objetivos. É importante ressaltar que existem aspectos importantes que devem ser levados em consideração, entre o que é "planejado" / prescrito e o que é realizado, pois ao realizar seu trabalho planificado, este professor cumpre um objetivo maior que certamente ultrapassa a esfera puramente escolar. Portanto, faz-se necessário que este profissional possa refletir, de forma crítica, sobre o que é realizado e proponha mudanças que promovam uma aprendizagem que atenda aos seus objetivos.

Amigues (2004) e Machado (2009) afirmam que se faz necessário evitar culpar os docentes e buscar enxergar os problemas existentes entre o que era para ter sido feito e o que foi feito; e principalmente entender que o aprendizado é mais do que a presença do aluno na escola cumprindo prescrições.

Temos consciência que o modo como foram gerados os dados desse estudo não é suficiente para traçar um panorama geral, mas é suficiente para evidenciar que é possível haver mudanças ao realizar uma avaliação de seu agir. O professor pode modificar e avaliar criticamente seu espaço, 
seu material e sua conduta a fim de modificar/ melhorar seu gênero profissional uma vez que PI reconhece não saber fazer a atividade proposta, mas aponta mudanças e estratégias dentro do seu agir para realizar a sua atividade docente de forma mais eficaz.

\section{REFERÊNCIAS BIBLIOGRÁFICAS}

ALVES Wanderson Ferreira. O trabalho docente (re) visitado. In: ALVES, Wanderson Ferreira Fialho. São Paulo: Papirus Editora, 2010, p.37-74.

AMIGUES, René. 2004. Trabalho do professor e trabalho de ensino. In: MACHADO, Anna Rachel. (Org.) $\mathbf{O}$ ensino como trabalho: uma abordagem discursiva. Londrina: Eduel. p.3553.

BRONCKART, Jean-Paul. 2006. Atividade de linguagem, discurso e desenvolvimento humano. Campinas, SP: Mercado de Letras.

BRONCKART, Jean-Paul. Por que e como analisar o trabalho do professor. IN: MACHADO, Anna Raquel e MATENCIO, Maria de lourdes M. (orgs.). Atividade de linguagem, discurso e desenvolvimento humano. Campinas, SP: Mercado de Letras, 2006.p. 203-231.

CLOT, Yves. A função Psicológica do Trabalho. São Paulo: Editora Vozes, 2007.

FAÏTA, Daniel. 2004. Gêneros de discurso, gêneros de atividade, análise da atividade do professor. O ensino como trabalho: uma abordagem discursiva. Londrina: Eduel. p. 55-80.

HABERMAS, Jürgen. Teoria do agircomunicativo1: racionalidade da açãoe racionalização social. Traduçãode Paulo Asttor Soethe. São Paulo: Editora WMF. Martins Fontes, [1929]2012.

LOUSADA, Eliane. Os pequenos grandes impedimentos da ação do professor: entre tentativas e decepções. In: MACHADO, Anna Raquel (org). O ensino como trabalho: uma abordagem discursiva. Londrina: EDUEL, 2004.

MACHADO, Anna Rachel. 2007. Colaboração e crítica: possíveis ações do lingüista na atividade educacional. In: Veredas On Line - Ensino. PPG Lingüística/ UFJF. Juiz de Fora -MG, fev., p.22-40.

Por uma concepção ampliada do trabalho do professor. In:

GUIMARÃES, Ana Maria de Mattos; MACHADO, Anna Raquel e COUTINHO, Antônia. O interacionismo sociodiscursivo: questões epistemológicas e metodológicas. São Paulo: Mercado das letras, 2007, p. 77-97.

Por uma clarificação do objeto de estudo 'trabalho do professor. In: GUIMARÃES, Ana Maria de M.; MACHADO, Anna Rachel \& COUTINHO, Maria Antônia (Orgs.). O interacionismo sociodiscursivo: questões epistemológicas e metodológicas. Campinas-SP: Mercado de Letras, 2006.

Trabalho prescrito, planificado e realizado na formação de professores: primeiro olhar. IN:CRISTOVÃO, Vera Lúcia Lopes e ABREU-TARDELLI, Lília Santos (orgs). Linguagem e Educação: o trabalho do professor em uma nova perspectiva. São Paulo: Mercado de Letras, 2009.

Por uma concepção ampliada do trabalho do professor. IN: GUIMARÃES A.M. de Matos; MACHADO, A. R.; COUTINHO, A. (orgs.) O interacionismo sociodiscursivo: questões epistemológicas e metodológicas. Campinas: Mercado de Letras, 2007.

MARTINY, Francieli F. "Eu não sei dar aula": representações de uma professora iniciante sobre o trabalgo docente. IN: MEDRADO, Betânia Passos \& PÉREZ, Mariana (orgs.). Leituras do agir docente: a atividade educacional a luz da perspectiva interacionista sociodiscursiva. Coleção: novas perspectivas em Linguística Aplicada. Vol12. Campina, SP: Pontes Editores, 2011. P. 157-176.

MUNIZ-OLIVEIRA, S. O trabalho do professor de pós-graduação: as marcas de pessoa e as vozes representadas. In: MACHADO, A.R.; LOUSADA, E.G. e FERREIRA, A.D. (Orgs). O professor e seu trabalho: a linguagem revelando práticas docentes. São Paulo: Mercado de Letras, 2011. P. 183-203. 
SILVA, C. O; BARROS, M.E. e LOUZADA, A.P. F. Clínica da atividade: dos conceitos às apropriações no Brasil. In: BENDASSOLI, L. A. (orgs). Clínicas do trabalho. São Paulo: Editora Atlas, 2011, p.188-207.

SOUZA-E-SILVA, M. C. P. 2004. "O ensino como trabalho". In: MACHADO, Anna Rachel. (Org.). O ensino como trabalho: uma abordagem discursiva. Londrina: Eduel. p. 81-104.

Recebido em 16/02/2017

Aceito em 14/06/2017

Publicado em 19/06/2017 